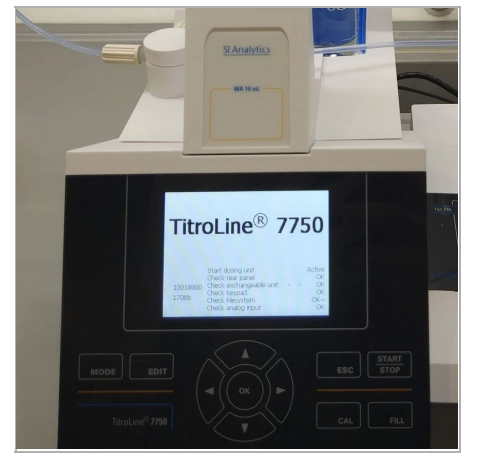

APR 02, 2019

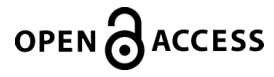

DOI:

dx.doi.org/10.17504/protocol s.io.wvcfe2w

Protocol Citation: Jonas Sundberg 2019.

Determination of the total acid number (TAN) in crude oils. protocols.io

https://dx.doi.org/10.17504/p rotocols.io.wvcfe 2 w

License: This is an open access protocol distributed under the terms of the Creative Commons Attribution License, which permits unrestricted use, distribution, and reproduction in any medium, provided the original author and source are credited

Protocol status: Working We use this protocol and it's working

Created: Jan 08, 2019

Last Modified: Apr 02, 2019

PROTOCOL integer ID: 19076

Keywords: Total acid number, petroleum, crude oil

\section{(3) Determination of the total acid number (TAN) in crude oils}

$\rightarrow$ In 1 collection

Jonas Sundberg ${ }^{1}$

${ }^{1}$ Technical University of Denmark

Sensors and Functional Materials

Chemistry Method Development Community

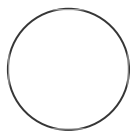

Jonas Sundberg

Technical University of Denmark

\section{ABSTRACT}

\section{Description}

Titrimetric determination of total acid number (TAN) in crude oil. Protocol is applicable to crude oils of medium acidity (approximately $0.5 \mathrm{mg} \mathrm{KOH} / \mathrm{g}$ ). Sample and reagent volumes should be adjusted if the TAN value is expected to be outside of this range.

\section{Instrumentation}

The analysis is carried out using a slightly modified version of ASTM 664 using a SI Analytics TitroLine 7750 (see attached documents for details of the original procedure).

\section{Reporting}

TAN values are reported in milligram of potassium hydroxide per gram of sample ( $\mathrm{mg}$ $\mathrm{KOH} / \mathrm{g})$.

\section{Quality control (QC) / system suitability test (SST)}

A synthetic oil containing a mixture of $\mathrm{C}_{13}, \mathrm{C}_{15}$ and $\mathrm{C}_{17}$ linear fatty acids (in 80:20 hexadecane:toluene) corresponding to to $0.5 \mathrm{mg} \mathrm{KOH} / \mathrm{g}$ is prepared and analyzed with each batch (maximum 6 oils). The value should be within $10 \%$ of the true value. 


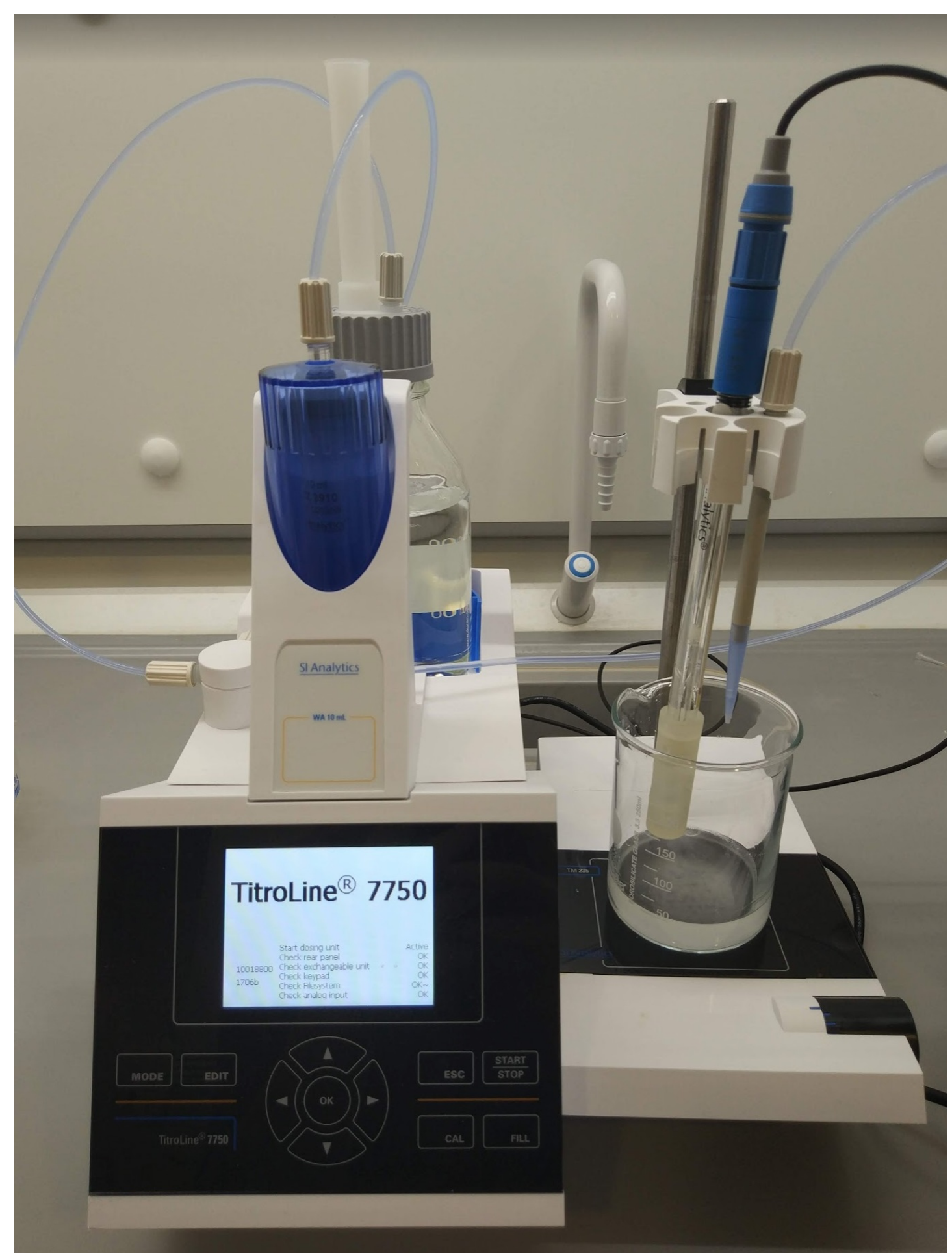

ATTACHMENTS

SIA-ApNote-ASTM-664Total-Acid-4477.pdf

QC_TAN_ASTM_664_31_0

1_19-10_58_53.pdf 
MATERIALS

MATERIALS

88 2-Propanol Merck MilliporeSigma (Sigma-Aldrich) Catalog \#190764

88 Hexadecane Sigma Aldrich Catalog \#H6703

88 Toluene Sigma Aldrich Catalog \#1.07019

88 Potassium hydroxide Sigma Aldrich Catalog \#1.05012

88 Potassium hydrogen phthalate Sigma Aldrich Catalog \#1.04874

88 Tridecanoic acid Sigma Aldrich Catalog \#91988

88 Pentadecanoic acid Sigma Aldrich Catalog \#91446

88 Heptadecanoic acid Sigma Aldrich Catalog \#H3500

STEP MATERIALS

88 2-Propanol Merck MilliporeSigma (Sigma-Aldrich) Catalog \#190764

89 Potassium hydroxide Merck MilliporeSigma (Sigma-Aldrich) Catalog

\#1050121000

\section{BEFORE START INSTRUCTIONS}

Check availability of the following standards and consumables:

- Titrant solution (6 g/L KOH in 2-propanol)

- Titration solvent (500:495:5 toluene:2-propanol:H2O)

- Potassium hydrogen phtalate

- Quality control sample $\left(\mathrm{C}_{13}+\mathrm{C}_{15+} \mathrm{C}_{17}\right.$ fatty acid in 80:20 hexadecane:toluene)

- Crude oil(s) (approximately $25 \mathrm{~mL}$ per sample)

Note

For preparation of standards, select "Appendix Preparation of consumables and standards" under Setup below.

Dissolution of $\mathrm{KOH}$ in 2-propanol proceeds slowly; titrant solution should be prepared one day in advance.

\section{Setup}

1 Assemble the titrator inside a ventilated fume-hood as samples are stored in open containers.

- Keyboard is optional, but highly recommended for entering of sample details.

- To store results as a PDF document, insert a USB memory stick (without encryption) into a USB-port 
in the back of the titrator. To avoid data loss, record results manually on paper.

- To ensure proper mixing, stirring should be used during all steps of the analysis. The stirrer bar should not touch the electrode, and spin at a low speed while stimulating proper mixing.

\section{Equipment}

TitroLine 7750

Titrator

SI Analytics

TL7750

Analysis

Appendix

\section{Prepare instrument for analysis}

$$
\text { step case }
$$

\section{Analysis}

Description of analytical workflow

2 The system is stored under $\mathrm{H}_{2} \mathrm{O}$. Remove water bottle, and replace with bottle filled with a suitable amount of titrant solution ( $6 \mathrm{~g} / \mathrm{L} \mathrm{KOH}$ in 2-propanol).

Note

Approximately $50 \mathrm{~mL}$ of titrant is used in calibration and blanking, followed by $5-6 \mathrm{~mL}$ per sample. 


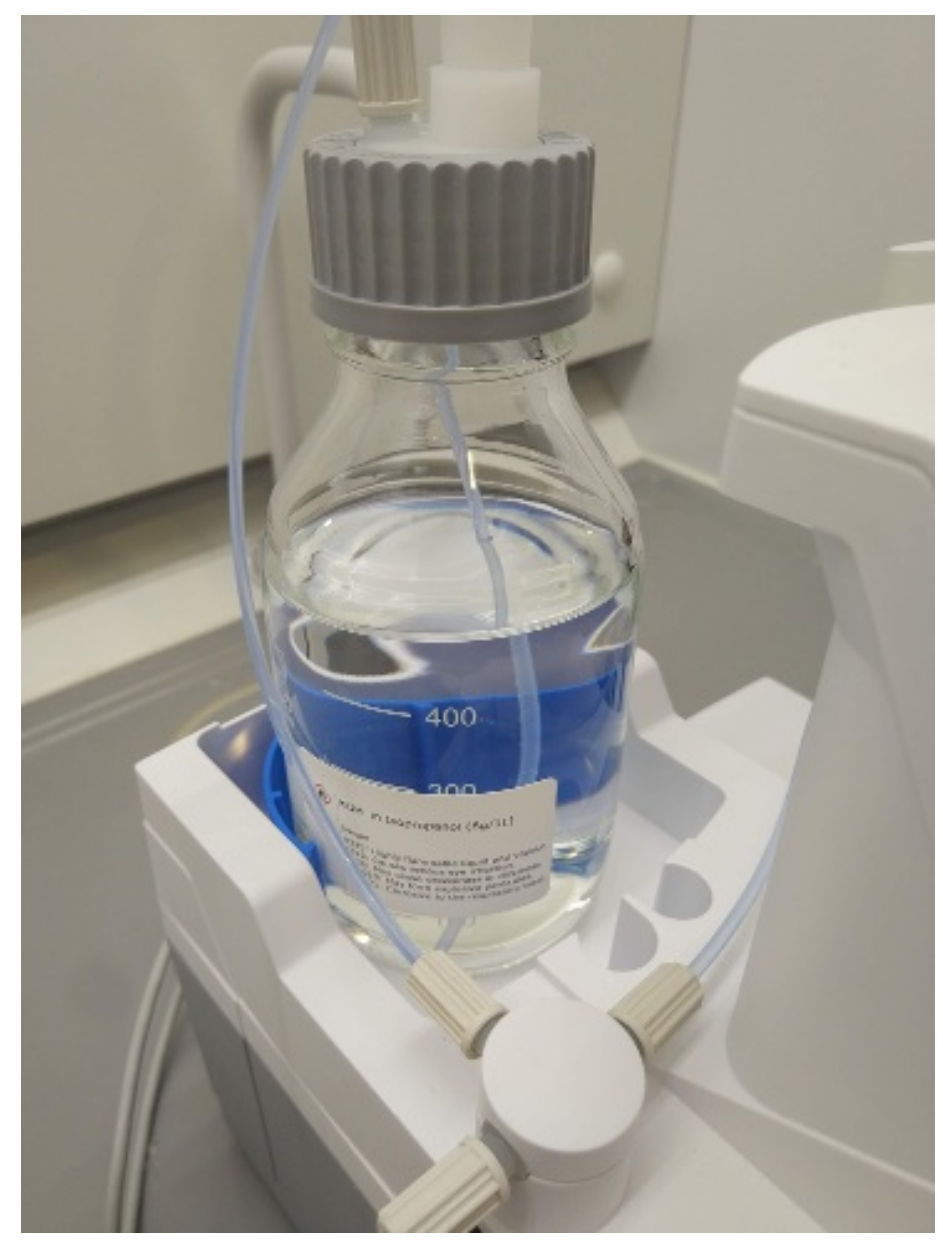

3

\section{Rinse syringe, tubing and pipette with titrant solution}

1. Click 'MODE'.

2. Select 'Rinsing'.

3. Place empty beaker under pipette.

4. Perform three consecutive rinses $(10 \mathrm{~mL}$ each).

5. Discard titrant waste.

\section{Calibrate titrant solution against freshly prepared KHP (aq., $12 \mathrm{mM}$ )}

1. Prepare three separate solutions of approximately $125 \mathrm{mg}$ potassium hydrogen phtalate (KHP) in $\mathrm{H}_{2} \mathrm{O}(50 \mathrm{~mL})$ in $100 \mathrm{~mL}$ beakers. Record the exact mass to two decimals.

2. Irrigate the beakers in a ultrasonic bath to facilitate dissolution.

3. When fully dissolved, place the first beaker on the titrator base.

4. Click 'MODE'.

5. Select 'Titer $\mathrm{KOH}$ '.

6. Click 'START'

7. Enter the exact measured weight of KHP.

8. After the measurement is finished, discard the solution and rinse the electrode with water. 
9. Repeat the calibration measurement on all three solutions. The average value is automatically saved in the unit.

\section{Expected result}

$0.09-0.11 \mathrm{M}(\% \mathrm{RSD}<5)$

Note

The experimentally measured value should be $0.1 \mathrm{M}$. A large deviation indicats an issue with either the titrant / KHP solution or instrument. Troubleshoot and continue when the issue has been identified and fixed.

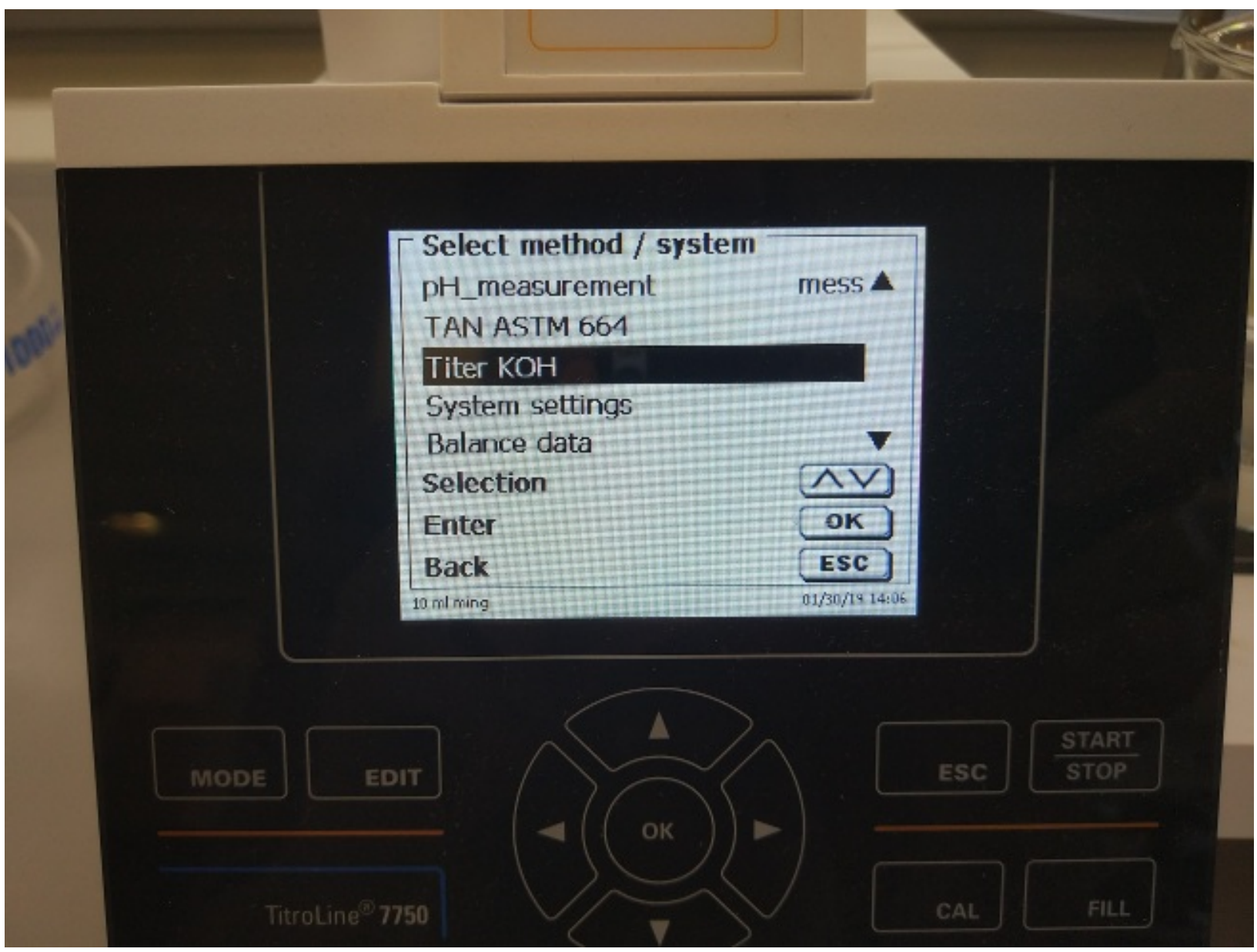


1. Transfer $100 \mathrm{~mL}$ of titration solvent to a $250 \mathrm{~mL}$ beaker with a stirring rod.

2. Click 'MODE'.

3. Select 'Blank TAN-TBN'.

4. Click 'START'

5. After the measurement is done, discard the solution and rinse the electrode with titration solvent, water and titration solvent again.

6. Repeat the blank measurement twice.

Validate instrument performance using QC sample

1. Weight 20 grams (approximately $25 \mathrm{~mL}$ ) of QC sample in a $250 \mathrm{~mL}$ beaker with a stirring rod. Record the exact mass to two decimals.

2. Dissolve the sample in $100 \mathrm{~mL}$ of titration solvent.

3. Click 'MODE'.

4. Select 'TAN ASTM 664'.

5. Click 'START'

6. Enter 'YYMMDD_QC' as sample name.

7. After the measurement is done, discard the solution and rinse the electrode with titration solvent, water and titration solvent again.

\section{Expected result}

$0.5 \mathrm{mg} \mathrm{KOH} / \mathrm{g}$

Note

The measured value must be within $10 \%$ of $0.5 \mathrm{mg} \mathrm{KOH} / \mathrm{g}$. If the value deviates, identify the issue before continuing. See attached documents under protocol description for a example QC titration.

\section{Sample measurement}

\section{Determine TAN for crude oil(s)}

1. Weight 20 grams (approximately $25 \mathrm{~mL}$ ) of crude oil sample in a $250 \mathrm{~mL}$ beaker with a stirring rod. Record the exact mass to two decimals.

2. Dissolve the oil in $100 \mathrm{~mL}$ of titration solvent.

3. Click 'MODE'. 
4. Select 'TAN ASTM 664'.

5. Click 'START' to start.

6. Enter weight, date and sample information.

7. After the measurement is done, discard the solution and rinse the electrode with titration solvent, water and titration solvent again.

8. Repeat until all samples have been measured.

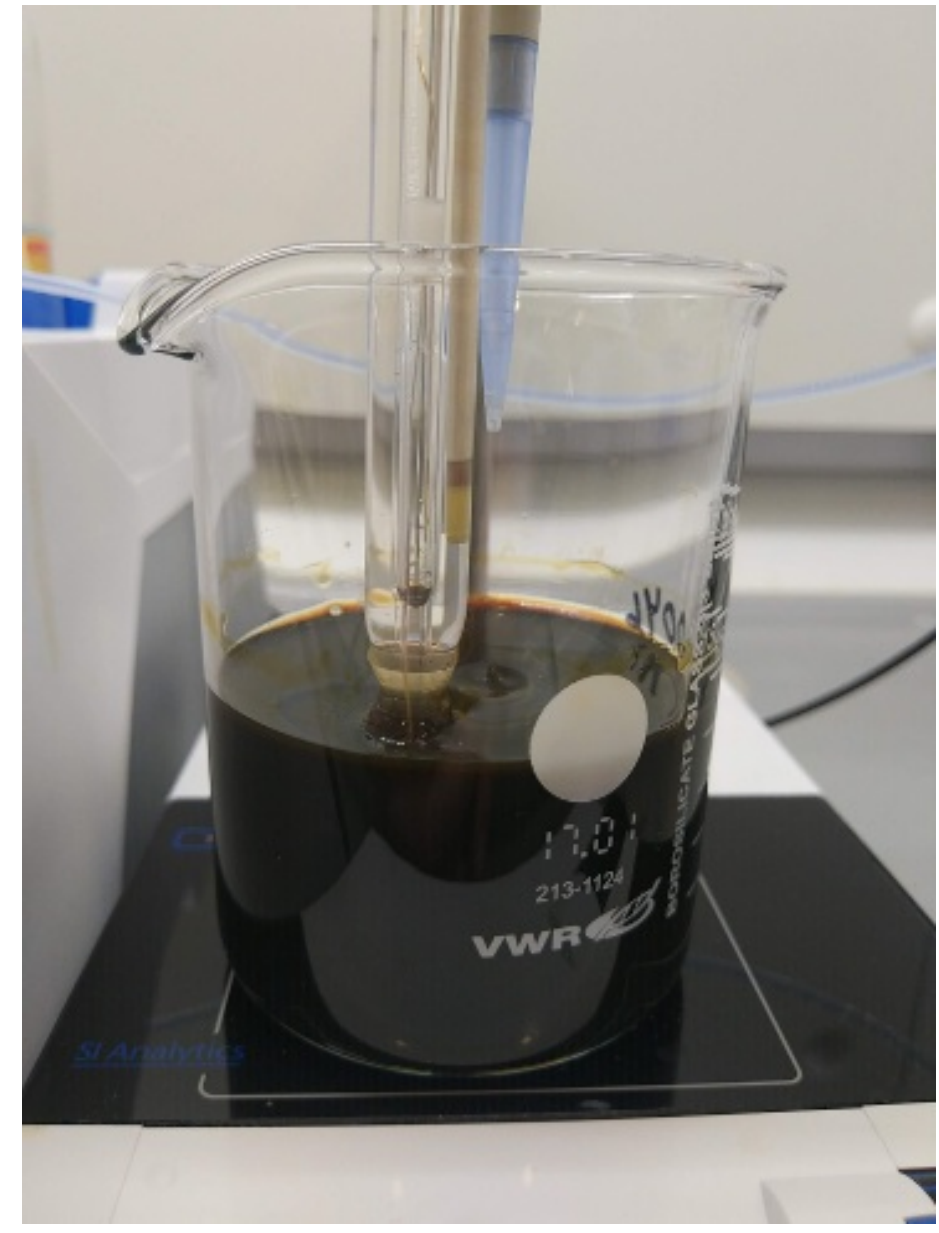

\section{Finishing}

8 When all samples have been measured, proceed with the following steps to prepare the instrument for storage:

1. Rinse electrode with titration solvent and water. If any (semi)-solid material have deposited on the electrode, remove it carefully using a lint-free Kimwipe.

2. Remove the titrant bottle and replace with bottle containing freshly prepared $\mathrm{H}_{2} \mathrm{O}$ (Milli-Q).

3. Place empty beaker under pipette.

4. Click 'MODE'.

5. Select 'Rinsing'. 
6. Click 'START'.

7. Perform three consecutive rinses $(10 \mathrm{~mL}$ each).

8. Turn off and disconnect system. 